\title{
Extrato de plantas medicinais como carrapaticida de Rhipicephalus (Boophilus) microplus
}

HOCAYEN, P.A.S. ${ }^{* *}$; PIMENTA, D.S. ${ }^{2}$

${ }^{1}$ Programa de Pós-Graduação em Farmacologia, Doutorado, Universidade Federal do Paraná - UFPR, Rua Brasílio Itiberê, Jardim Botânco, 206, apt. 211, CEP: 80210-060, Curitiba-Brasil *pallomaas@yahoo.com.br; ${ }^{2}$ Universidade Federal de Juiz de Fora, Instituto de Ciências Biológicas, Departamento de Botânica, Campus Universitário, Martelos, CEP: 36036-900, Juiz de Fora-Brasil

RESUMO: O uso de plantas medicinais tem sido uma prática antiga da humanidade, contribuindo para a divulgação das virtudes terapêuticas de extratos de diferentes vegetais. Na busca de alternativas naturais eficazes para males que prejudicam indiretamente o homem, as plantas medicinais têm sido utilizadas na veterinária na tentativa de eliminar ou reduzir a ação dos carrapatos $B$. microplus, que podem trazer prejuízos a bovinos. Durante anos têm sido utilizado produtos químicos nesse controle, no entanto, os carrapatos adquirem resistência aos fármacos em decorrência do uso contínuo. Assim, objetivou-se avaliar o efeito de hidrolato e extratos aquosos de carqueja [Baccharis trimera (Less). D.C.], alfavaca (Ocimum gratissimum L.), necroton [Vernonia condensata (Backer) H. Rob.] camomila [Chamomilla recutita (L.) Rauschert], além do óleo essencial de alfavaca (Ocimum gratissimum L.). Os ensaios para larvas de $B$. microplus foram realizados com impregnação das substâncias em papel filtro. Os resultados obtidos demonstraram que todos os extratos aquosos foram ineficazes; o hidrolato de carqueja e de necroton apresentaram eficiência em torno de $30 \%$, necessitando novos testes para comprovação. Dentre os resultados obtidos, destaca-se o hidrolato de alfavaca que apresentou eficiência de $76,7 \%$ na concentração de $100 \%$ e o óleo essencial puro de alfavaca que apresentou ação larvicidade $100 \%$ indicando o potencial carrapaticida dessa planta, especificamente no combate de B.microplus.

Palavras-chave: carrapato, Baccharis trimera, Ocimum gratissimum, Vernonia condensata, Chamomilla recutita.

ABSTRACT: Herbal extract against Rhipicephalus (Boophilus) microplus ticks. The use of medicinal plants has been a longstanding practice of mankind, helping to spread the therapeutic virtues of different plant extracts, due to their medicinal effects. In the search for effective natural alternatives for ailments that indirectly affect man, medicinal plants have been used in veterinary medicine, in an attempt to eliminate or reduce the action of B. microplus ticks, which can cause damage to cattle. For many years, chemical products have been used in this control. However, after some time ticks acquire drug resistance, as a result of continuous use. Thus, the objective of this paper was to evaluate the effect of hydrolates and aqueous extracts of carqueja [Baccharis trimera (Less). DC], alfavaca (Ocimum gratissimum L.), necroton [Vernonia condensata (Baker) H. Rob.], chamomile [Chamomilla recutita (L.) Rauschert] and also the essential oil of alfavaca (Ocimum gratissimum L.). The assays for larvae of $B$. microplus were carried out by impregnating the paper filter with the substances. The results showed that all the aqueous extracts were ineffective; the hydrolate of carqueja and necroton presented efficiencies around $30 \%$, requiring further tests to prove. Among the results, we observed that the alfavaca hydrolate showed an efficiency of $76.7 \%$ at a concentration of $100 \%$ and the pure alfavaca oil showed a larvicidal action of $100 \%$, indicating this plant's potential to reduce ticks, specifically in the control of B. microplus.

Keywords: tick, Baccharis trimera, Ocimum gratissimum, Vernonia condensata, Chamomilla recutita.

Recebido para publicação em 30/07/2010 


\section{INTRODUÇÃO}

O uso das plantas medicinais pelo homem é uma prática antiga, sendo empregada em diversos grupos étnicos em todo o mundo (Martins, 2000). Destaca-se que ao longo da história o desenvolvimento de pesquisas direcionadas a aplicação de plantas medicinais apresentou grande avanço científico, envolvendo estudos químicos e farmacológicos, que, em função de diferentes técnicas experimentais, dedicaram-se a obter novas substâncias com potencial terapêutico (Chechinel Filho \& Yunes, 1998).

Segundo Lorenzi \& Matos (2002), a busca de propriedades medicinais em plantas permite descobrir aquelas que podem contribuir efetivamente na recuperação e na manutenção do bem estar dos organismos. Dessa forma, cada vez mais procura-se extratos naturais eficientes para utilização no controle de organismos maléficos que estão diretamente associados a males que assolam os seres vivos, levando-se em consideração o fato de que as alternativas apresentadas não tragam efeitos adversos para o ambiente e para os organismos.

Do mesmo modo, observa-se na medicina veterinária o emprego de extratos de plantas medicinais com o intuito de eliminar ou reduzir o impacto da ação de diferentes parasitas, ressaltandose o combate ao carrapato $B$. microplus, que pode acarretar grandes prejuízos à saúde dos bovinos e, conseqüentemente, a rentabilidade dos produtores.

O carrapato dos bovinos é um ectoparasita relevante na veterinária, que causa perdas diretas e indiretas aos animais de maneira em geral, pela transmissão de doenças e pelo elevado custo de seu controle. É um parasita que apresenta alta incidência e prevalência nas condições brasileiras e também em países desenvolvidos de clima tropical como a Austrália. Assim, em função da complexidade das interações entre o parasita e o hospedeiro, agravado pelo desconhecimento dos pecuaristas sobre informações específicas, é necessário a adoção de praticas efetivas para controlar este artrópodo (Rocha, 1995).

Segundo Santos et al. (2000), o controle desse carrapato é realizado principalmente na fase parasitária, por meio de produtos químicos, e a utilização inadequada desses produtos induz resistência aos carrapaticidas, bem como contaminação ao homem e ao meio ambiente.

Wharton (1976) apud Souza et al. (2003) afirma que cepas resistentes a acaricidas aparecem por seleção e recombinações de genes resistentes em populações de carrapatos expostas a pressões de seleção por carrapaticidas. Segundo Nolan (1990), basicamente insetos e carrapatos resistentes conseguem escapar da eficiência de um produto por meio da redução na taxa de penetração do carrapaticida no carrapato; mudanças no metabolismo, armazenamento e excreção do produto; e mudanças no local de ação, possibilitando ao carrapato menor sensibilidade aos efeitos deletérios desses produtos.

Aspectos relacionados à resistência de $B$. microplus aos acaricidas (Leite, 1988), a demanda dos consumidores por alimentos livres de resíduos químicos e a procura por produtos que não prejudiquem o ambiente, tem acelerado a busca por extratos de plantas com efeito carrapaticida.

Nesse contexto Borges et al. (2003) relataram que Melia azedarach, conhecida vulgarmente como cinamomo ou Santa Bárbara tem sido empregada para o controle de $B$. microplus. Prates et al. (1998) em estudo com capim-gordura, salienta que o monoterpeno 1,8-cineol e seu emprego, na concentração de $10,6 \%$, foi capaz de matar $100 \%$ das larvas desse carrapato. $O$ efeito inseticida do composto 1,8-cineol forneceu resultados para a broca Rhyzopertha dominica (F.) e para o besouro Tribolium castaneum (Herbst).

Com o objetivo de avaliar o efeito carrapaticida sobre larvas de carrapatos de B. microplus, foram empregados extratos das plantas carqueja [Baccharis trimera (Less). D.C.], alfavaca (Ocimum gratissimum L.), necroton [Vernonia condensata (Backer) H. Rob.] e camomila [Chamomilla recutita (L.) Rauschert].

\section{MATERIAL E MÉTODO}

As plantas foram coletadas pela manhã no horto da Faculdade de Farmácia e Estação de Cultivo e Manutenção de Plantas da Universidade Federal de Juiz de Fora - UFJF. Posteriormente foram levadas para o laboratório acondicionadas em sacos plásticos, etiquetadas e armazenadas em freezer a $-18^{\circ} \mathrm{C}$.

Os extratos aquosos foram preparados a partir de: i) Alfavaca - folhas; ii) Camomila amarela - flores; iii) Necroton - folhas; e iv) Carqueja - partes aladas do caule. Utilizou-se $12 \mathrm{~g}$ de cada espécie vegetal triturando com $25 \mathrm{~mL}$ de água destilada, com o auxílio de pilão e pistilo, durante $10 \mathrm{~min}$. Após a maceração a solução obtida foi filtrada em funil de vidro, com algodão, e o filtrado coletado em bequer de $50 \mathrm{~mL}$. Cada uma das quatro plantas produziram aproximadamente $15 \mathrm{~mL}$ de extrato, o qual foi armazenado em freezer $-18^{\circ} \mathrm{C}$ ao abrigo da luz para a posterior utilização nos testes larvicidas.

Também foi feita a extração dos óleos essencias de carqueja, alfavaca e necroton. Utilizando-se $200 \mathrm{~g}$ de cada droga vegetal para a obtenção dos respectivos óleos essenciais. 
A extração foi realizada por hidrodestilação em Clevenger por duas horas. Ao final do processo de extração foram obtidas soluções emulsificantes, hidrolatos, enquanto que somente no caso da alfavaca pode-se obter, separadamente, o óleo essencial puro e o respectivo hidrolato.

Os hidrolatos de carqueja, alfavaca e necroton, o óleo essencial de alfavaca e os extratos aquosos de carqueja, alfavaca, necroton e camomila foram testados no laboratório de parasitologia da Embrapa Gado de Leite, para controle do carrapato $B$. microplus. Os testes foram realizados segundo a metodologia proposta por Leite (1988), na qual foram inseridas aproximadamente 100 larvas entre papéis filtro de $2 \times 2 \mathrm{~cm}$ recém impregnados pelos extratos, hidrolatos e óleo que formaram um 'sanduíche'. Após a primeira etapa, o material foi depositado em envelope também de papel filtro de $4 \times 4 \mathrm{~cm}$ e vedado, estufa climatizada a $\pm 27^{\circ} \mathrm{C} \mathrm{e}$ UR de $80 \%$, contando-se o número de larvas vivas e mortas após $24 \mathrm{~h}$.

Os extratos aquosos, hidrolatos e o óleo essencial foram testados em três concentrações (25, 50 e 100\%). Em todas as diluições (hidrolatos, óleo e extratos) utilizou-se água destilada como controle negativo enquanto para o controle positivo foi utilizado o Flytion ${ }^{\circledR}$. Os testes foram realizados em triplicata.

\section{RESULTADOS}

Todos os resultados obtidos com os extratos, hidrolatos e óleo das plantas analisadas, foram examinados de maneira quantitativa, realizando-se a contagem entre o número de larvas de $B$. microplus que se mantiveram vivas e mortas após $24 \mathrm{~h}$.
De acordo com os resultados apresentados na Tabela 1, não foi observada mortalidade de $B$. microplus em presença dos extratos aquosos de Baccharis trimera, Ocimum gratissimum, Vernonia condensata e Chamomilla recutita.

O hidrolato de Baccharis trimera, nas concentrações de $25 \%$ e $50 \%$, não apresentou eficácia frente às larvas de carrapato, e somente na concentração de $100 \%$ foi observado índice de mortalidade de $34 \%$ das larvas.

Já o hidrolato de Vernonia condensata apresentou eficácia de $31,4 \%$ na menor concentração (25\%), 49,2\% na concentração média (50\%), e $33,3 \%$ na concentração mais elevada (100\%).

Em relação à aplicação do hidrolato de Ocimum gratissimum, observou-se mortalidade nas três concentrações analisadas (25\%, 50\% e 100\%), porém, destacam-se os resultados apresentados na concentração mais elevada (100\%), na qual a mortalidade das larvas foi superior a $75 \%$.

Por fim, a realização do teste com o óleo de Ocimum gratissimum apresentou mortalidade superior a $74 \%$ nas três concentrações analisadas (25\%, $50 \%$ e $100 \%)$,e mortalidade total na maior concentração (100\%). O resultado da mortalidade das larvas na aplicação do óleo em relação ao seu hidrolato, pode ter sido devido ao óleo essencial estar puro e não emulsificado com água como no hidrolato, maximizando assim, o efeito larvicida desta planta medicinal.

\section{DISCUSSÃO}

A eficacia das espécies testadas no combate ao carrapato foi distinta para cada planta ou extrato. Os extratos aquosos das plantas medicinais testadas não apresentaram capacidade

TABELA 1. Percentagens médias (dp) de larvas de Rhipicephalus microplus mortas (M) e vivas (V) em extratos, hidrolatos e óleo essencial de Chamomilla. Recutita, Baccharis trimera, Vernonia condensata e Ocimum gratissimum.

\begin{tabular}{|c|c|c|c|c|c|c|c|}
\hline \multirow{3}{*}{ Testes realizados } & & \multicolumn{6}{|c|}{ Concentrações } \\
\hline & & \multicolumn{2}{|c|}{$25 \%$} & \multicolumn{2}{|c|}{$50 \%$} & \multicolumn{2}{|c|}{$100 \%$} \\
\hline & & v & $\mathbf{M}$ & v & M & v & M \\
\hline C. recutita & Extrato aquoso & $100(0,0)$ & $0(0,0)$ & $100(0,0)$ & $0(0,0)$ & $100(0,0)$ & $0(0,0)$ \\
\hline \multirow{2}{*}{ B. trimera } & Extrato aquoso & $100(0,0)$ & $0(0,0)$ & $100(0,0)$ & $0(0,0)$ & $100(0,0)$ & $0(0,0)$ \\
\hline & Hidrolato & $100(0,0)$ & $0(0,0)$ & $100(0,0)$ & $0(0,0)$ & $65,9(24,6)$ & $34,0(24,6)$ \\
\hline \multirow{3}{*}{ V. condensata } & Extrato aquoso & $100(0,0)$ & $0(0,0)$ & $100(0,0)$ & $0(0,0)$ & $100(0,0)$ & $0(0,0)$ \\
\hline & Hidrolato & $68,5(54,5)$ & $31,4(54,5)$ & $50,7(19,0)$ & $49,2(19,0)$ & $66,6(57,7)$ & $33,3(57,7)$ \\
\hline & Extrato aquoso & $100(0,0)$ & $0(0,0)$ & $100(0,0)$ & $0(0,0)$ & $100(0,0)$ & $0(0,0)$ \\
\hline \multirow[t]{2}{*}{ O. gratissimum } & Hidrolato & $79,2(18,0)$ & $20,7(18,0)$ & $83,6(24,7)$ & $16,3(24,7)$ & $23,2(37,1)$ & $76,7(37,1)$ \\
\hline & Óleo & $25,3(19,3)$ & $74,6(19,3)$ & $16,1(22,7)$ & $83,8(22,7)$ & $0(0,0)$ & $100(0,0)$ \\
\hline Controle negativo & & $100(0,0)$ & $0(0,0)$ & $100(0,0)$ & $0(0,0)$ & $100(0,0)$ & $0(0,0)$ \\
\hline Flytion® & & $0(0,0)$ & $100(0,0)$ & $0(0,0)$ & $100(0,0)$ & $0(0,0)$ & $100(0,0)$ \\
\hline
\end{tabular}

Rev. Bras. PI. Med., Campinas, v.15, n.4, supl.I, p.627-631, 2013. 
larvicida; contudo, destaca-se que os hidrolatos demonstraram potencial carrapaticida.

Em trabalhos anteriores, como o realizado por Borges et al. (2003), obteve-se grande eficácia nos diferentes extratos obtidos do fruto maduro de $M$. azedarach sobre larvas e fêmeas ingurgitadas deste carrapato. Neste estudo os autores obtiveram ainda a inibição total da postura de ovos e mortalidade de quase $100 \%$ das larvas, observadas na concentração de $0,25 \%$, quando o hexano foi usado para a obtenção do extrato, demonstrando que nem todos os extratos são ineficazes como carrapaticidas.

Os resultados obtidos com as emulsões de $B$. trimera e $V$. condensata, mostraram-se favoráveis, mas, observa-se a necessidade de serem conduzidos mais testes, especificamente utilizando o óleo essencial e não somente a emulsão, na tentativa de alcançar um efeito carrapaticida mais proeminente.

Nos testes realizados com o hidrolato, destaca-se a planta Ocimum gratissimum que obteve ação larvicida, com eficiência elevada na maior concentração (100\%). Desse modo, pode-se concluir que o hidrolato de Ocimum gratissimum tem também potencial de aplicação como carrapaticida. No teste com o óleo, o efeito foi potencializado, ressaltando que na maior concentração ocorreu mortalidade de $100 \%$ das larvas.

Em trabalhos realizados por Chagas et al. (2002) com óleos essenciais de espécies de Eucalyptus em larvas e fêmeas de $B$. microplus foram obtidos resultados eficientes na mortalidade dessas larvas, comprovando assim o poder carrapaticida de certas plantas medicinais.

Assim, a partir dos dados apresentados por diferentes estudos, pode-se afirmar que os resultados obtidos corroboram para a comprovação de que o possível efeito carrapaticida esperado não se encontra nas plantas como um todo, como pôde ser observado também nos resultados descritos na tabela 1. Desse modo, remete-se que o possível efeito positivo no combate a carrapatos está diretamente relacionado a substâncias específicas que estão presentes no óleo essencial.

Corroborando, no trabalho realizado por Prates et al. (1998), destacou-se o efeito de um componente existente no óleo essencial do capim-gordura como responsável pelo efeito contra o carrapato $B$. microplus. Tal substância é o monoterpeno 1,8-cineol encontrado na concentração de $10,6 \%$, que foi capaz de matar $100 \%$ das larvas do carrapato $B$. microplus em 5 minutos. Do mesmo modo, Lorenzi \& Matos (2002), identificaram que o óleo de Ocimum gratissimum possui na sua composição, dentre vários componentes, 0 monoterpeno 1,8-cineol, na concentração de 12,1\%, resultado este que permite concluir que o efeito carrapaticida encontrado em Ocimum gratissimum nos testes realizados (conforme Tabela 1) pode ser decorrente da existência deste mesmo monoterpeno 1,8-cineol, que foi responsável pelos resultados satisfatórios encontrados em pesquisas realizadas com o capim-gordura. Contudo, salienta-se a necessidade de pesquisas direcionadas ao estudo dos componentes presentes no óleo essencial de Ocimum gratissimum, objetivando o isolamento de compostos.

Sendo assim, pode-se concluir que os experimentos realizados contribuem com a tentativa de encontrar na natureza alternativas eficientes para combater $B$. microplus, destacando-se, neste trabalho, os resultados obtidos com a aplicação do óleo essencial de Ocimum gratissimum, que apresentou importante eficácia carrapaticida.

\section{REFERÊNCIA}

BORGES, L.M.F. et al. In vitro efficacy of extracts of Melia azedarach against Boophilus microplus. Medicine Veterinary Entomology, v.17, p.228-231, 2003.

CECHINEL FILHO, V.; YUNES, R.A. Estratégias para a obtenção de compostos farmacologicamente ativos a partir de plantas medicinais. Conceitos sobre modificações estruturais para otimização da atividade. Química Nova, v.21, n.1, p.99-105, 1998.

CHAGAS, A.C.S. et al. Acaricide effect of Eucalyptus spp essential oils and concentrated emulsion on Boophilus microplus. Brazilian Journal of Veterinary Research and Animal Science, v.39, n.5, p.247-253, 2002.

LEITE, R.C. Boophilus microplus (Canestrini, 1887): susceptibilidade, uso atual e retrospectivo de carrapaticida em propriedades da região fisiogeográficas da baixada do Grande-Rio e Rio de Janeiro, uma abordagem epidemiológica. 1988. 122p. Tese (Doutorado - Área de concentração em Medicina Veterinária) - Departamento de Medicina Veterinária, Universidade Federal Rural do Rio de Janeiro, Rio de Janeiro.

LORENZI, H.; MATOS, F.J.A. Plantas medicinais no Brasil: nativas e exóticas. 2.ed. São Paulo: Plantarum, 2002. 512p.

MARTINS, P.M. Influência da temperatura e da velocidade do ar de secagem no teor e na composição química do óleo essencial de capimlimão P. (Cymbopogon citratus (D.C.) Stapf). 2000. 77p. Dissertação (Mestrado - Área de concentração em Engenharia Agrícola) - Departamento de Engenharia Agrícola, Universidade Federal de Viçosa, Viçosa.

NOLAN, J. Acaricide resistance in single and multi-hosts ticks and strategies for control. Parasitologia, v.32, n.1, p.145-53, 1990.

PRATES, H.T. et al.Identification of some chemical components of the essential oil from molasses grass (Melinis minutiflora Beauv.) and their activity against catle-tick (Boophilus microplus). Journal of the Brazilian Chemical Society, v.9, n.2, p.193-197, 1998.

Rev. Bras. PI. Med., Campinas, v.15, n.4, supl.I, p.627-631, 2013. 
ROCHA, C.M.B.M. Caracterização da percepção dos produtores do município de Divinópolis/MG sobre a importância do carrapato Boophilus microplus e fatores determinantes das formas de combate utilizadas. 1995. 205p. Dissertação (Mestrado - Área de concentração em Medicina Veterinária Preventiva) - Departamento de Medicina Veterinária, Universidade Federal de Minas Gerais, Belo Horizonte.
SANTOS, J.C.; FURLONG, J.; DAEMON, E. Controle do carrapato Boophilus microplus (acari: Ixodidae) em sistemas de produção de leite da microrregião fisiográfica Fluminense do Grande Rio - Rio de Janeiro, RJ. Ciência Rural, v.30, n.2, p.305-311, 2000.

SOUZA, A.P. et al. Efficacy of acaricides in dairy cattle herds in southern region of Paraná state, Brazil. Revista de Ciências Agroveterinárias, v.2, n.2, p.131-135, 2003. 